\title{
"O estremecer de uma súbita esperança": os camponeses da Cotinguiba e a negociação pela terra no tempo de Dom Luciano Duarte
}

\author{
"The shudder of a sudden hope": the peasants of Cotinguiba and negotiation \\ for land in the time of Don Luciano Duarte
}

Magno Francisco de Jesus Santos*

\begin{abstract}
Resumo
O final dos anos 60 do século XX, em Sergipe, foi marcado pela eclosão de uma série de conflitos em torno da posse da terra e da ausência de trabalho. Em um período no qual os movimentos sociais eram tidos como manifestações de subversão, a luta dos camponeses da região da Cotinguiba foi tratada como questão policial, por meio da repressão e da prisão dos líderes. Esse artigo busca analisar o processo de negociação entre os camponeses sergipanos da Cotinguiba e as elites políticas e agrárias nas ações de instituição da reforma agrária no estado sob a mediação da Arquidiocese de Aracaju. Essa negociação resultou na criação da Promoção do Homem do Campo de Sergipe (PRHOCASE) e na formação de fazendas comunitárias sob a tutela do arcebispo metropolitano de Aracaju, Dom Luciano Duarte. Com isso, se torna possível compreender as ações do clero na negociação entre camponeses e latifundiários.
\end{abstract}

Palavras-chave: reforma agrária, Dom Luciano, Arquidiocese de Aracaju, trabalhadores rurais.

\begin{abstract}
The late 60 s of the twentieth century, in Sergipe, was marked by the outbreak of a series of conflicts over land tenure and lack of work. In a period in which social movements were seen as subversive demonstrations, the struggle of the peasants of the region Cotinguiba was treated as a police matter, through repression and arrest of leaders. This article seeks to analyze the process of negotiation between the peasants of Sergipe Cotinguiba and the political and agrarian elites in the land reform process institution in the state under the mediation of the Roman Catholic Archdiocese of Aracaju. This negotiation resulted in the creation of the Promotion of Sergipe Field Man (PRHOCASE) and the formation of community farms under the supervision of the Metropolitan Archbishop of Aracaju, Dom Luciano Duarte. With this, it becomes possible to understand the actions of the clergy in the negotiation between peasants and landowners.
\end{abstract}

Keywords: agrarian reform, Dom Luciano, Roman Catholic Archdiocese of Aracaju, rural workers.

Artigo submetido em 10 de dezembro de 2016 e aprovado em 02 de dezembro de 2017.

* Professor do Departamento de História da UFRN. Doutor em História pela UFF. Desenvolve pesquisas sobre ensino de história, religiosidades, festas e devoção. País de Origem: Brasil. E-mail: magnohistoria@gmail.com

Horizonte, Belo Horizonte, v. 15, n. 48, p. 1480-1503, out./dez. 2017 - ISSN 2175-5841 


\section{Introdução}

$\mathrm{O}$ alvorecer dos anos 60 do século XX foi marcado pela emergência de importantes rupturas políticas, econômicas e sociais no cenário brasileiro. No âmbito político, destacou-se a instabilidade que desencadeou o golpe de 1964, com a instauração da ditadura civil-militar e, consequentemente, o aumento da repressão às ações de resistência e aos movimentos sociais organizados por estudantes e trabalhadores. No âmbito social, destacavam-se os movimentos de organização e resistência das ligas camponesas, na reivindicação por direitos frente aos latifundiários (ANDRADE, 1989).

A ditadura brasileira, entre 1964 e 1985, era respalda pela aliança entre militares e diferentes setores da sociedade civil, como a imprensa, grandes proprietários, elite política e segmentos da elite eclesiástica. Esse apoio civil, especialmente ao longo dos anos 60, tinha como respaldo discursivo a manutenção da ordem e o combate à ameaça das ideias comunistas.

Com isso, os segmentos sociais que eram considerados pelas elites políticas e religiosas como mais propensos à disseminação de ideias atreladas ao marxismo, como estudantes e trabalhadores rurais e urbanos, passaram a ser alvo da atenção de importantes setores vinculados ao Estado brasileiro por meio da repressão policial. Além disso, em decorrência do apoio da elite eclesiástica ao golpe e da constante ação de vigilância e combate ao marxismo por parte do clero, tais grupos também passaram a ser alvo de ações executadas pelas pastorais da Igreja Católica. Essa atuação ambígua de religiosos em defesa do governo ditatorial promoveu a emergência de uma leitura na qual privilegia uma radical oposição entre o clero tido como progressista e opositor aos militares, frente ao clero classificado como conservador e vinculado ao governo (ALMEIDA, 2016).

Essa ambivalência se torna mais complexa no âmbito das ações da Igreja Católica frente à questão da terra no Brasil ao longo da segunda metade do século XX. Antes mesmo da deflagração do golpe de 1964, já ecoavam vozes discordantes 
sobre as ações a serem tomadas em relação às precárias condições de vida dos trabalhadores rurais. De acordo com Osvaldo Heller da Silva, "a militância efetiva junto às populações rurais começou no Nordeste, onde os bispos decidiram lançar uma campanha de sindicalização para 'fazer a reforma agrária e combater o comunismo e a esquerda”" (SILVA, 2006, p. 220). Desse modo, as ações católicas em relação à questão da terra coadunavam com o "clima de terror anticomunista, alardeado que o Brasil estava às portas de cair na anarquia e nas malhas da violência e do ateísmo" (AZZI, 2001, p. 446).

O medo do comunismo teria propiciado o envolvimento de diferentes setores da Igreja Católica na questão da terra, incluindo o grupo tido como mais reacionário. No entender de Lucili Grangeiro Cortez, “a questão principal, para esse grupo, era fixar o trabalhador rural à terra para evitar o êxodo e a proletarização, havendo, assim, necessidade de impedir que se tornasse vulnerável à agitação e ao aliciamento dos comunistas" (CORTEZ, 2005, p. 73). Com isso, os trabalhadores rurais eram transformados em pequenos proprietários, protegidos pela organização de sindicatos rurais, que, paulatinamente deixavam de ser "uma organização assistencial, para ter uma ação ativa" (CORTEZ, 2005, p. 73). Para Antônio Torres Montenegro, a oposição entre católicos e comunistas fez com que "três forças (Igreja, PCB e Ligas) disputassem o controle do movimento dos trabalhadores rurais" (MONTENEGRO, 2010).

Entretanto, essa dicotomia entre católicos e comunistas no processo de disputa pelo agenciamento dos movimentos dos trabalhadores rurais não mensura uma questão relevante: as tensões internas entre católicos de esquerda e de direita. O clero católico brasileiro, ao longo da segunda metade do século XX, matizado por diferentes diretrizes políticas, incluía setores que apoiariam o golpe de modo irrestrito, os que se posicionaram contrários, os que oscilaram no posicionamento ao longo dos governos militares e os que usaram da aproximação do governo para defender setores perseguidos pelo Estado. Sob a designação católica era possível encontrar diferentes posicionamentos em relação ao governo e a situação dos 
trabalhadores rurais. De acordo com Riolando Azzi, as tensões entre a Igreja Católica e o regime civil-militar foram ambíguas e dinâmicas:

Embora inicialmente a instituição católica tivesse, através de suas forças mais representativas, manifestado simpatia e até apoio à tomada de poder pelos militares, pressionada pelo medo do comunismo, essa adesão foi pouco a pouco sendo abandonada por parte de algumas lideranças, na medida em que se acentuava no novo regime a violação dos direitos humanos (AZZI, 2001, p. 454).

Portanto, a partir da experiência dos religiosos em relação aos movimentos sociais no período da ditadura civil-militar, nos deparamos com uma realidade muito mais complexa, na qual o limiar entre o apoio ao governo e o engajamento nas causas dos movimentos trabalhistas nem sempre se tornam visíveis. Esse certamente foi o caso da atuação de Dom Luciano Duarte, então bispo Auxiliar da Arquidiocese de Aracaju, na resolução dos conflitos entre trabalhadores rurais e fazendeiros na região açucareira da Cotinguiba, em Sergipe.

Dom Luciano tornou-se um importante aliado dos militares em Sergipe, assumindo o protagonismo na criação de instituições culturais e educacionais, como a Universidade Federal de Sergipe ou ocupando cargos de destaque em Brasília, especialmente no Conselho Nacional de Educação. Além disso, essa aproximação com os militares fez com que o religioso fosse recorrentemente interpelado por familiares para mediar na defesa de cidadãos perseguidos pelos militares. Essa condição de mediador na trajetória de Dom Luciano é foco desta análise, que tem como questão central a compreensão sobre a atuação de Dom Luciano Duarte como mediador entre as elites políticas, econômicas e intelectuais de Sergipe e os camponeses da região da Cotinguiba. Essa negociação tornou-se possível a partir do reconhecimento dos referidos camponeses como sujeitos de suas ações, com a valorização das experiências das camadas populares como instrumento de reconhecimento dos problemas sociais.

Nos anos 60 do século XX, a região até então marcada pela presença de dezenas de usinas de açúcar, monocultura da cana e grande propriedade, passou 
por significativas mudanças estruturais, com o fechamento das usinas e o aumento drástico do desemprego. Essas mudanças repercutiram no engajamento dos trabalhadores rurais em manifestações contra as péssimas condições de vida que prevaleciam na região. Diante das ações de repressão às manifestações dos trabalhadores rurais na cidade sergipana de Maruim, com a prisão, teve início a atuação do prelado no processo de negociação com as autoridades policiais, políticas e econômicas no sentido de amenizar os problemas enfrentados pelos trabalhadores.

Certamente, essa atuação de Dom Luciano Duarte expressa uma fissura na imagem de um religioso que destacou pelo combate à Teologia da Libertação e apoio ao governo civil-militar. Desse modo, torna-se possível discutir a experiência de reforma agrária empreendida pela Igreja Católica a partir das ações de negociação entre Dom Luciano, os trabalhadores que passariam a ser conhecidos como “agricultores de Dom Luciano” e as elites políticas e econômicas sergipanas.

Este artigo tem como foco a discussão do envolvimento do então bispo auxiliar da Arquidiocese de Aracaju, Dom Luciano Duarte, no processo de criação da Promoção do Homem do Campo de Sergipe (PRHOCASE). Esse órgão, ao longo da segunda metade do século XX, tornou-se a principal experiência de reforma agrária em Sergipe, por meio da aquisição de fazendas para serem redistribuídas entre os trabalhadores rurais que viviam em situação de extrema pobreza.

As chamadas fazendas comunitárias foram implantadas entre 1968 e 1972, tornando-se o principal trabalho social da Arquidiocese de Aracaju no último quartel do século XX. Por meio da PRHOCASE, as antigas fazendas de monocultura de cana-de-açúcar, transformavam-se em fazendas comunitárias, com uma produção voltada para a subsistência e inserção dos antigos trabalhadores em proprietários. Uma experiência de reforma agrária acompanhada até 1988 por voluntários vinculados a Arquidiocese. 
Com isso, este artigo tem como fonte a documentação produzida pela Arquidiocese de Aracaju e, principalmente, os textos de memórias escritos por Dom Luciano Duarte, nos quais apresentam algumas questões atinentes ao processo de fundação da PRHOCASE. Esses textos foram localizados no Arquivo da PRHOCASE, na Cúria Arquidiocesana de Aracaju e no Instituto Dom Luciano Duarte, responsável pela salvaguarda da documentação atinente a atuação do religioso em diferentes âmbitos da sociedade.

\section{1 “Um grito de angústia": a Igreja Católica e a questão da terra}

Os anos sessenta do século XX foram marcados pela eclosão de uma série de problemas sociais, econômicos e políticos. Foi um momento de incertezas acerca do futuro, de instabilidade vivenciada no presente. Foi uma década de reconstrução dos governos e da instauração de um novo regime político, sob o comando de uma elite formada pela aliança civil-militar, que repercutiu no cerceamento das liberdades individuais. ${ }^{1}$ Essa situação apresenta uma conotação mais crítica em espaços marcados pela pobreza da população, como a região sergipana do vale do Cotinguiba. Foi nas "veredas poéticas”2 e miseráveis dessa região, que ecoou a voz dos marginalizados, o suspiro dos oprimidos, "o grito de angústia"3 capaz de sensibilizar os ouvidos dos prelados sergipanos e levar a criação de uma das iniciativas mais promissoras no campo da inserção social: a PRHOCASE.4

A região da Cotinguiba, 5 historicamente, é uma das mais importantes áreas produtivas de Sergipe. Sua relevância já era reconhecida desde a primeira metade

\footnotetext{
${ }^{1}$ O historiador Ibarê Dantas entende que a intervenção dos militares na política nacional deve ser qualificada como uma "contrarrevolução, tanto pelo seu caráter preventivo e neutralizador das tendências que se esboçavam, quanto pelo seu sentido propositivo" (DANTAS, 2014, p. 12).

${ }^{2}$ Essa expressão é utilizada pelo historiador José Mário dos Santos Resende para designar os campos da Cotinguiba açucareira (RESENDE, 2003).

${ }^{3}$ De acordo Dom Luciano Cabral Duarte, Luiz Alves, advogado, funcionário do Banco do Brasil e supervisor desse banco junto à "Cooperativa do 13", foi quem primeiramente utilizou esse termo para designar o processo de criação da PRHOCASE. Nas palavras do bancário: “A PRHOCASE nasceu de um grito de angústia" (DUARTE, 1978, p. 3).

${ }^{4}$ Promoção do Homem do Campo de Sergipe.

${ }^{5}$ A região da Cotinguiba é constituída pelos seguintes municípios: Capela, Divina Pastora, Santa Rosa de Lima e Siriri. Além disso, existe a região da Baixa Cotinguiba, com importante produção açucareira, integrada pelos municípios de Carmópolis, General Maynard, Laranjeiras, Maruim, Riachuelo, Rosário do Catete e Santo Amaro das Brotas.
} 
do século XIX (NUNES, 1978), por meio da emergência da produção açucareira e do desenvolvimento de vilas e cidades cercadas por canaviais e engenhos. Foi assim que ocorreu o surgimento de povoações como Maruim, Laranjeiras, Riachuelo e Rosário (ALMEIDA, 1978). A riqueza vinha da cana. Entretanto, junto à riqueza havia a miséria. A exclusão social também crescia junto aos canaviais. Primeiramente, com a exploração da mão-de-obra de africanos escravizados. Posteriormente, em tempos republicanos, com a continuidade do uso de trabalhadores rurais, em formas de subemprego. Sob a égide de uma suposta liberdade, a miséria permaneceu como a fiel inquilina dos lares de trabalhadores rurais na região canavieira.

Esse cenário de "reordenamento do trabalho" foi discutido exaustivamente pelo principal expoente da história econômica sergipana, Josué Modesto dos Passos Subrinho. Ele explica como a região canavieira adentrou o período republicano com a gradativa substituição do trabalho escravo por uma mão-deobra assalariada, com trabalhadores que viviam nas cercanias das usinas e, nos períodos de colheita, com o uso do trabalho temporário dos camponeses oriundos de outras localidades (PASSOS SUBRINHO, 2000).

Ao longo do século XX, o processo de modernização das usinas sergipanas foi lento e conservador, como atestou Ibarê Dantas (2004). Essas mutações graduais perpassaram o tempo e pouco repercutiram no modo de vida dos expropriados. Em dias republicanos, Sergipe vivenciou uma continuidade de sua estrutura agrária dos tempos imperiais. Como elucidavam os camponeses, eram tempos das desilusões. Diante disso, temos como escopo o sofrimento dos pequenos e o sonho, por vezes esquecido. Trata-se das aventuras e desafios enfrentados por Luciano Duarte e seus agricultores no processo de criação da PRHOCASE e a luta pela transformação da vida de famílias camponesas.

O início dos governos militares no Brasil delineou o desencadeamento de significativas transformações na economia dos municípios da região da Cotinguiba 
sergipana. Cidades que em outrora produziam uma importante parcela das riquezas no estado, passavam por um momento de estagnação, de assolamento da produção. Nas palavras de Dom Luciano Duarte, a região "vivia mais um lance de sua inexorável decadência” (DUARTE, 1978, p. 3). Isso ocorreu tanto pela demissão dos trabalhadores das fazendas e usinas de açúcar, como também por meio do fechamento das fábricas de tecidos. ${ }^{6}$ Neste setor, especificamente, a crise das fábricas era decorrente da inabilidade de manutenção da concorrência no mercado. Ricardo Lacerda Melo explicita essa questão:

Ao lado dos dados positivos, apresentam-se, de forma bastante intensa, os aspectos negativos sobre o setor têxtil regional. Isto ocorre devido a incapacidade do antigo parque fabril de se adaptar ou de competir com as fábricas do Centro-Sul e, agora, com as unidades produtivas recéminstaladas na região a partir da política de incentivos do Governo Federal. Assim, diversas fábricas tiveram de encerrar as atividades e o desemprego gerado não é compensado com a entrada em funcionamento das fábricas modernas (MELO, 1987, p. 12).

Percebe-se como a indústria têxtil nordestina passava a enfrentar sérios problemas, em decorrência da baixa produtividade e qualidade dos produtos e falta de investimentos (MELO, 1987, p. 37-38). Na região da Cotinguiba, os efeitos dessa crise industrial foram devastadores, pois não havia espaço de reinserção dos trabalhadores desempregados. Além disso, no campo existia outro elemento que tornava a situação ainda mais drástica: o latifúndio. A desigualdade social em Sergipe era gritante e um dos reflexos disso era a elevada concentração de terras nas mãos de uma pequena elite latifundiária. A professora Maria Lúcia Berger ressalta essa questão:

Como ocorre na grande maioria dos Estados brasileiros, em Sergipe verifica-se também que, enquanto uma minoria da população dispõe de maior poder aquisitivo e da posse de grande parcela da terra cultivável a qual nem sempre é realmente explorada, a maior parte dos habitantes rurais vive numa situação de marginalização econômica e social (BERGER, 1982, p. 77).

\footnotetext{
${ }^{6}$ Entre o final do século XIX e início do século XX, foram criadas dezenas de fábricas de tecidos nos principais municípios sergipanos, tornando-se um promissor mercado de trabalho para famílias que fugiam das secas e buscavam melhores condições de vida em centros urbanos como Aracaju, São Cristóvão, Estância, Neópolis, Propriá e Maruim. Ao longo da segunda metade do século XX, essas fábricas perdem espaço no mercado, sem poder de concorrência e começam a declarar falência e serem fechadas (DANTAS, 2004).
} 
A terra era um elemento de distinção social e certamente um dos graves problemas enfrentados nos embates políticos. Essa temática acirrou os impasses entre os interesses de grupos antagônicos, despertou o medo sobre a questão da reforma agrária e da expansão das ideias comunistas, levou lideranças a escreverem contra o marxismo, 7 até a deflagração do golpe. Por outro lado, os defensores das reformas eram vistos pela elite política e econômica com desconfiança, como uma ameaça à soberania nacional e à propriedade privada. Um indício dessa realidade conflituosa é o discurso proferido por Seixas Dória, o então governador de Sergipe, na noite posterior ao golpe, "reafirmando sua disposição de permanecer na luta em favor das reformas estruturais" (DANTAS, 2014, p. 22).

Nesse sentido, o discurso em defesa da reforma agrária passou a ser visto pelas elites econômicas e eclesiásticas como um indício expressivo da propagação do socialismo para o Brasil. Ibarê Dantas explica como "o patronato rural, então, depois de assistir, na defensiva, ao crescimento da campanha pela reforma agrária, questionando o direito de propriedade, acolhia o regime autoritário de forma exultante" (DANTAS, 2014, p. 59-60). Aparentemente, as propostas de executar reformas no sentido de promover a redistribuição das terras e reduzir as desigualdades sociais foram sepultadas na madrugada de primeiro de abril de 1964. Em Sergipe, apesar de apresentarem diferentes posicionamentos políticos, os três prelados apoiaram o golpe de 1964, por meio de publicações elogiosas acerca da atuação dos militares no combate ao comunismo. Esse posicionamento seria relativizado no início da década de 70, momento no qual o bispo da Diocese de Propriá, Dom José Brandão de Castro, aproximou-se das ideias da Teologia da Libertação e passou a exercer críticas ao governo e à situação social de seu território diocesano.

\footnotetext{
7 Um caso elucidativo sobre isso é a constante produção no jornal católico "A Defesa", do bispo da Diocese de Propriá, Dom José Brandão de Castro, contra a difusão dos ideais comunistas e os perigos provocados pelos governos tidos como progressistas para a família brasileira. Esses textos foram publicados principalmente no momento imediatamente anterior ao golpe e nos primeiros meses após a deflagração. Para Ibarê Dantas, dentro do grupo de religiosos que apoiavam os militares estavam Duarte e "até o Bispo de Propriá (SE), D. José Brandão de Castro, que posteriormente intrépido defensor das causas dos trabalhadores rurais e dos índios" (DANTAS, 2014, p. 40).
} 
Contudo, os problemas do campesinato sergipano permaneciam incautos. As condições de vida eram extremamente precárias e a situação tornou-se ainda mais delicada com a redução das oportunidades de emprego em decorrência do fechamento de fábricas e de fazendas. ${ }^{8}$ Os trabalhadores desempregados passaram a reivindicar seus direitos e a se organizar por meio dos sindicatos dos trabalhadores rurais. Entre os anos 50 e 60 do século XX, ocorreu uma expansão dos sindicatos rurais, muitas vezes criados sob a tutela da Igreja Católica, por meio de órgãos como a Ação Católica, Juventude Universitária Católica e Movimento de Educação de Base. Um caso emblemático dessa aproximação entre o clero e os camponeses expropriados ocorreu na Arquidiocese de Natal, no Rio Grande do Norte, no início dos anos 60 do século XX. Foi uma iniciativa do chamado Movimento de Natal, que passou a construir uma proposta de intervenção da Igreja acerca dos problemas sociais. De acordo com o cardeal Dom Eugênio Sales: 9

A causa, no fundo, é a mesma. Na cidade há muitos recursos. No interior não há recursos. Então precisávamos aglomerar, reunir, cuidar da promoção pelo associativismo, porque não havia quase nada nesse sentido. Havia cerca de seis a sete sindicatos rurais no Brasil. E praticamente era vetada a criação de associação rural, porque havia medo do comunismo. E eu insistir. Fui até o Presidente da República, argumentar. Criamos a primeira federação do meio rural. Foi no Rio Grande do Norte. Depois veio a Confederação Nacional. Mas não havia os sindicatos rurais e nem era possível criar os sindicatos, porque o governo não favorecia. Mas a Igreja entrou com seu apoio moral, prestígio moral, para insistir, porque, através do associativismo, há proteção da pessoa (SALES, 2009, p. 17).

A entrevista concedida por Dom Eugênio Sales expressa, de forma contundente, a relevância da Igreja Católica no apoio a organização dos trabalhadores rurais. O Movimento de Natal consistia na reunião de seis padres da Arquidiocese de Natal, preocupados com a luta social, especialmente, a população

\footnotetext{
${ }^{8} \mathrm{O}$ problema relativo às fazendas, ao longo da década de 60 do século $\mathrm{XX}$, era a gradativa substituição da produção de açúcar pelas pastagens voltadas para a pecuária. Com isso, ocorreu uma drástica redução da demanda de mão-de-obra, aumentando consideravelmente o quadro de desemprego na microrregião da Cotinguiba. Antônio José Nascimento revela um aumento das pastagens nessa microrregião na ordem de 125\% (NASCIMENTO, 1994, p. 67).

9 Dom Eugênio de Araújo Sales atuou como Bispo Auxiliar de Natal entre 1954 e 1961 e administrador apostólico da mesma arquidiocese entre 1962 e 1965. Em 1957, na Colônia de Punaú, ele coordenou uma pioneira experiência de colonização e reforma agrária. No dia 15 de junho de 1962 fundou a FETARN (Federação dos Trabalhadores Agrários do Rio Grande do Norte). Ele nasceu em Acari, no Rio Grande do Norte, em 1920. Foi nomeado cardeal pelo Papa Paulo VI em 1969. Atuou como arcebispo da Arquidiocese de São Salvador da Bahia (1968-1971) e da Arquidiocese do Rio de Janeiro (1971-2001). Faleceu em 2012.
} 
do campo. Ele foi um dos precursores de uma ação mais sistemática do clero em relação à questão social. De acordo com Maria José Costa Fernandes:

Até os anos 1960, os trabalhadores rurais não existiam socialmente. Não havia nenhuma legislação específica, realidade que se reproduz até a existência dos Movimentos e organização política dos trabalhadores rurais de forma mais efetiva. A partir daí, eles passaram a ser vistos, tornando-se objeto de Política Pública. O Rio Grande do Norte não está à parte dessa conjuntura política, pois o que aconteceu no Estado é fruto de uma mobilização nacional, encabeçada pelo Movimento Sindical, Igreja Católica e partidos de esquerda (FERNANDES, 2013, p. 357).

Percebe-se como o problema agrário era uma tônica da sociedade brasileira, especialmente, no Nordeste. Talvez por esse motivo, essa região tenha sido um espaço de propulsão de iniciativas no sentido de arregimentar os trabalhadores rurais e apresentar propostas de organizações sindicais e de reformas agrárias. Algumas dessas ações, como as de Dom Hélder Câmara, em Recife e Olinda; Dom Eugênio de Araújo Sales, em Natal; Dom José Távora, em Aracaju e Dom José Brandão de Castro, em Propriá (Sergipe), são consideravelmente estudadas e apresentadas como referências no engajamento da Igreja Católica no campo social. Outras iniciativas, entretanto, não foram alvo de tantas pesquisas e, de certa forma, foram silenciadas como experiências frutíferas do engajamento de prelados brasileiros na questão da reforma agrária. Esse é o caso da atuação de Dom Luciano Duarte.

\section{2 "A narração das amarguras": Dom Luciano e os trabalhadores}

A experiência sergipana de aproximação do clero nas questões sociais da terra emergiu nos idos de 1967, no município de Maruim. Além da falta de emprego no campo, provocada pela substituição das plantações de cana pelas pastagens, a indústria têxtil da cidade, a "Sergipe Fabril",10 declarou falência e encerrou suas atividades em outubro do mesmo ano. De acordo com Dom Luciano Duarte, "a

\footnotetext{
${ }^{10}$ De acordo com Cid Olival Feitosa, a Sergipe Fabril foi fundada na cidade de Maruim nos idos de 1926, ano no qual também foi criada outra indústria têxtil na Cotinguiba, a "Fábrica de Tecidos Riachuelo". Isso expressa uma ação na tentativa de dinamizar a economia da região que se destacava no cenário estadual pela produção do açúcar (FEITOSA, 2007, p. 35).
} 
Fábrica de Tecidos existente naquela cidade fechara suas portas em situação precária, e os operários aguardavam, impacientes, a regularização de seu problema, de acordo com as leis trabalhistas" (DUARTE, 1978, p. 3).

O momento do fechamento da fábrica de tecidos era de agitação no pequeno município na Cotinguiba. Os operários estavam sindicalizados e mostravam a insatisfação com a lentidão do processo para atender aos seus direitos. Por outro lado, havia o sindicato dos trabalhadores rurais, que estava em fase de organização e iniciava o arregimento de camponeses. Contudo, a situação tornou-se mais delicada no final do mês de outubro, quando algumas casas amanheceram pichadas com palavras de ordem associadas aos movimentos trabalhistas, como "operário que não luta morre de fome" (DUARTE, 1978, p. 3). A pichação foi vista pelas elites como uma afronta à ordem, uma ameaça de luta proletária, o anúncio do conflito.

Em tempos de censura e de forte repressão aos suspeitos de perturbação à ordem pública, de imediato ocorreu uma denúncia na Secretaria de Segurança Pública, com a solicitação de intervenção. O medo do comunismo era o alimento reacionário. Na sociedade brasileira ditatorial, as denúncias eram recorrentes, fato que, quase sempre levava a prisão os suspeitos de conspiração contra o regime, para serem alvo de inquéritos instaurados pelos militares. Com isso, quando o funcionário da Secretaria de Segurança Pública de Sergipe adentrou a cidade de Maruim, a população indicou onde estava "todo líder trabalhista conhecido como tal" (DUARTE, 1978, p. 3). O resultado dessa ação foi o aprisionamento de grande parte dos líderes de movimentos trabalhistas que viviam na cidade, inclusive alguns representantes do Sindicato dos Trabalhadores Rurais, conduzidos "presos para a Secretaria de Segurança Pública, em Aracaju” (DUARTE, 1978, p. 3).

Tais prisões geraram inquietações na cidade de Maruim, especialmente com os familiares dos trabalhadores presos. Isso também repercutiu na Arquidiocese de Aracaju. Nessa época, o arcebispo Dom José Vicente Távora já se encontrava com problemas de saúde e estava internado no Hospital São José. Como asseverou o 
historiador Ibarê Dantas, Dom Távora estava com a "saúde abalada, diabético e cardíaco" (DANTAS, 2014, p. 234). Mesmo internado, o arcebispo metropolitano de Aracaju enviou um bilhete para o seu bispo auxiliar, Dom Luciano Duarte, para que o mesmo comparecesse ao referido hospital. No entardecer, em conversa entre os dois clérigos, Dom Távora solicitou a Dom Luciano para que fizesse "o possível para solucionar o impasse" (DUARTE, 1978, p. 4).

A intervenção do clero em problemas de detenção das camadas populares e de estudantes era recorrente no período da ditadura civil-militar. Era nesse contexto de prisões muitas vezes arbitrárias, nas quais os bispos católicos usavam de seu prestígio no sentido de proteger cidadãos e defender a garantia dos direitos humanos. Isso era possível em decorrência do bom relacionamento construído entre alguns religiosos e os militares. Um caso elucidativo dessa situação foi a do Cardeal Dom Avelar Brandão, arcebispo Primaz do Brasil de São Salvador da Bahia. Ele tornou-se um elo de diálogo entre os militares e também ponto de apoio para os líderes da resistência de esquerda. Para Zachariadis,

O bom relacionamento que D. Avelar procurava manter com as Forças Armadas, permitia a ele ter um grande espaço de manobra para interceder em defesa dos religiosos que trabalhavam em sua diocese e, principalmente, conseguir protegê-los contra a repressão militar (ZACHARIADIS, 2009).

Essa dualidade no processo de construção de alianças e na proteção levou muitos dos prelados brasileiros a serem vistos com desconfiança pelas autoridades civis e militares. São casos exemplares disso os bispos Dom Avelar Brandão Vilela na Bahia e Dom Vicente Távora em Sergipe (DANTAS, 2014, p. 40). Mesmo assim, em não raros momentos foi possível vislumbrar a presença de tais religiosos intercedendo junto aos militares para evitar o prosseguimento de inquéritos. Isso ocorreu em março de 1970, quando Dom Távora, preocupado com o religioso canadense padre Dion, "interveio junto ao delegado da Polícia Federal, empenhando-se para evitar os interrogatórios” (DANTAS, 2014, p. 236). 
Esse tipo de interpelação também foi comum na trajetória de Dom Luciano Duarte. A sua biógrafa, Gizelda Morais, apresenta inúmeros casos nos quais o prelado sergipano buscou atestar a não filiação ao comunismo dos membros da Juventude Universitária Católica, perseguidos pelos militares. Além disso, ela ressalta "o apoio de D. Luciano a favor das pessoas que sofreram repressões nos primeiros anos do regime militar, fora do âmbito da JUC" (MORAIS, 2008, p. 233). Nesse caso, a sua interpelação acerca dos trabalhadores rurais de Maruim seria apenas mais uma ação de negociação com os militares.

Em Sergipe, até aquele momento, a trajetória de Dom Luciano Duarte estava atrelada ao campo cultural, com especial atenção para a questão educacional. Como ele mesmo afirma no catálogo comemorativo dos dez anos da PRHOCASE, "de 1948 (quando fui ordenado sacerdote) até 1966 (quando fui eleito Bispo Auxiliar de Aracaju), meu trabalho sacerdotal esteve sempre ligado a Educação" (DUARTE, 1978 , p. 4-6). Ele tinha atuado de forma quase que onipresente no processo de implantação do ensino superior no Estado, primeiramente com a fundação da Faculdade Católica de Filosofia de Sergipe, nos idos de 1951. Depois como membro do Conselho Estadual de Educação já defendia a proposta de fundar uma universidade no estado. Por fim, já como bispo auxiliar, também em 1967, com a liderança no processo de criação da Universidade Federal de Sergipe. Percebe-se como o momento de criação da PRHOCASE era pouco propenso para a agregação de novas atividades, pois o religioso estava totalmente engajado na causa do ensino superior e na articulação com as autoridades federais no sentido de agilizar o trâmite.

Mesmo assim, naquela mesma noite do incidente, Dom Luciano saiu do Hospital São José e se dirigiu até a residência do então secretário de Segurança Pública, o coronel Joalbo Figueiredo. Lá foi negociada a libertação dos trabalhadores. De acordo com as memórias do religioso: 
Recebido com atenção, expliquei-lhe o que acontecera.

Perguntou-me o Secretário: - "Que providências o sr. Deseja?"

- Pediria que os presos fossem devolvidos às suas famílias quanto antes, ainda hoje.

- O sr se responsabiliza por eles?

- Inteiramente.

O Coronel Joalbo chamou então um auxiliar e mandou que o mesmo me acompanhasse à Secretaria de Segurança, com ordem de entregar-me todos os presos de Maruim, cerca de sete ou oito homens. O que foi feito em seguida (DUARTE, 1978, p. 4).

Naquela noite de outubro de 1967, sob a intervenção de Dom Luciano, os trabalhadores rurais voltavam livres para seus respectivos lares. Mais do que isso! Nascia ali o sonho de construção de uma liberdade mais sólida. Ao se deparar com os prisioneiros, acusados de perturbação, o bispo sergipano enxergou na pálida feição dos excluídos, a perturbadora ação da miséria que assolava o país.

\section{3 “Os agricultores de Dom Luciano": a criação da PRHOCASE}

No duplo intento de cumprir sua promessa ao coronel da segurança pública e de buscar ouvir as inquietações dos camponeses, Dom Luciano prometeu visitar a sede do sindicato em Maruim. Após essa proposta, ele liberou a famosa Kombi da Arquidiocese de Aracaju para levar os trabalhadores para Maruim, onde as famílias os aguardavam. O primeiro encontro do religioso com as camadas populares de Maruim foi breve, permeado de poucas palavras, possivelmente quase todas de agradecimento pelo empenho na liberação. Contudo, ali germinavam as primeiras inquietações no sentido de se constituir uma ação mais consistente, de aproximar a Igreja Católica dos dilemas do seu povo e, também de propor uma solução que distanciasse de um viés marxista.

No domingo seguinte, após a celebração da missa na Igreja de São Salvador e de participar do programa "A Hora Católica" na Rádio Cultura de Sergipe, Dom Luciano cumpriu sua promessa e deslocou-se para Maruim, para visitar os trabalhadores rurais e ouvir os seus problemas. No "Dia do Senhor", o bispo conhecido por seu intelecto, doutor em Filosofia pela Sorbonne, era surpreendido 
pelas palavras de angústias de homens e mulheres que nunca havia frequentado a escola. Ele, inicialmente, solicitou aos presentes à reunião para "contar com simplicidade suas dificuldades, seus problemas, seus dramas, a pena de sua vida" (DUARTE, 1978, p. 4). Na pequena sala do Sindicato Rural de Maruim, Dom Luciano ouvia "a narração das amarguras" de cerca de cinquenta homens e mulheres que foram para a reunião.

Na sequência da reunião, o religioso perguntou sobre o que seria necessário para a melhoria de suas vidas. Surpreendentemente, a resposta veio em coro: "duas coisas: o Instituto (isto é: a Previdência Social) e terra para a gente plantar nossa comida" (DUARTE, 1978, p. 4). A sabedoria popular revelava o grande dilema vivenciado pelo homem do campo: a falta da terra, repercutida na ausência do pão de cada dia. As vozes dos trabalhadores direcionavam para o problema enfrentado e criava a expectativa do sacerdote ilustrado apontar para uma solução. Por esse motivo, é pertinente afirmar que a PRHOCASE nasceu do grito de angústia dos camponeses da Cotinguiba. Emergia a partir da confluência entre o poder de negociação do clero e a experiência das camadas populares rurais.

Outra questão relevante apontada nesse contexto é que muitos dos camponeses presentes na reunião trabalhavam nas fazendas e nas usinas da região, mas mesmo assim não possuíam as mínimas condições de sustento, em decorrência dos baixos salários. Como elucidou Dom Luciano Duarte, "o pagamento era muito baixo, cerca de um pouco mais de cinco cruzeiros por dia" (DUARTE, 1978, p. 6). Essa assertiva reflete o nível de exploração existente na microrregião que produzia as maiores riquezas do estado. O poderio dos senhores continuava na dependência da exploração dos lavradores. ${ }^{11}$ Além disso, ao longo do

\footnotetext{
${ }_{11}^{11}$ De acordo com as afirmações dos camponeses para Dom Luciano, os fazendeiros da Cotinguiba costumavam ceder parte de suas propriedades para que os trabalhadores a utilizassem para a agricultura de subsistência. Contudo, após o preparo da terra, do desmatamento e de cultivar por um ou dois anos, os proprietários se apropriavam do lote para usá-lo no cultivo da cana ou como pastagens, levando os lavradores a se submeterem a reiniciar o processo de preparo da terra em outro ponto da fazenda, ou seja, o auxílio era mais uma estratégia de expansão das atividades produtivas por áreas de difícil acesso, preparadas gratuitamente pelos meeiros. Confira a explicação desse processo no catálogo dos 10 anos da PRHOCASE, com o relato de Dom Luciano Duarte (DUARTE, 1978, p. 6).
} 
final dos anos 60 e início dos anos 70, a situação foi agravada com a crise econômica que levou ao fechamento de parte considerável das usinas açucareiras.

Após ouvir os clamores do povo, o bispo auxiliar da Arquidiocese de Aracaju utilizou uma de suas principais habilidades para tentar encontrar a solução do grande dilema. Emergia a faceta do mediador, do homem de negociação, de diálogo entre os diferentes segmentos da sociedade local, no intuito de implantar uma instituição capaz de apresentar respostas seguras, sem ameaças de ideologias contraditórias ao sistema político e a própria doutrina da Igreja, mas que fosse efetivamente capaz de melhorar as condições de vida da população. Com isso, ele passou a atuar em três frentes: negociação com usineiros, busca de apoio técnico entre os intelectuais e diálogo com lideranças políticas. Buscou angariar apoio em diferentes setores da sociedade, no sentido de construir uma proposta que não fosse voltada exclusivamente para a distribuição de terras, mas sim, voltada para a formação cidadã respaldada na própria terra.

Primeiramente, conversou com membros da elite latifundiária, no sentido de ficar a par da situação das terras na região e das condições de trabalho das camadas populares. Era o passo inicial para gestar a PRHOCASE. De acordo com Luciano Duarte:

A situação era trágica, e a alegação, conforme comprovei depois, junto a proprietários de terra amigos meus, era verdadeira, na quase generalidade dos casos. Que fazer?

Enquanto a ideia de que era preciso fazer algo concreto martelava a cabeça, comecei a conversar com alguns proprietários de terra com quem tinha aproximação. Dois nomes estão nessas raízes longínquas da PRHOCASE: Hélber Ribeiro e Joaquim Maynart. Ambos acolheram a ideia com entusiasmo, confirmando a pobreza e miséria da grande maioria dos camponeses de toda aquela região da Cotinguiba (DUARTE, 1978, p. $6)$.

Percebe-se como o então bispo auxiliar foi hábil no processo de constituição da PRHOCASE. Ele buscou amparo inicialmente com os grandes proprietários da região, no sentido de buscar outros olhares acerca do problema social. Além disso, era um mecanismo para conseguir apoio dos latifundiários na causa da 
redistribuição de terras, bem como, evitar ser visto como articulador de uma iniciativa inspirada no marxismo. Essa dissociação era uma preocupação na atuação do bispo. Ele queria constituir uma atuação da Arquidiocese que trilhasse uma terceira via: destoante do capitalismo e oposta ao comunismo.

É importante ressaltar o modo pelo qual foi pensada a reforma agrária da PRHOCASE. A ideia consistia na compra de fazendas, na divisão em lotes e consequentemente na distribuição entre os camponeses, para que os mesmos pudessem cultivar produtos que auxiliassem no sustento da família. Uma questão relevante nesse processo e que certamente determinou a conquista do apoio dos fazendeiros era o fato desses lotes não serem voltados para a completa emancipação dos trabalhadores, mas sim para o complemento da renda, para ser somado "aos baixos salários" recebidos nas usinas. Com isso, evitava-se, por parte dos usineiros, a perda da garantia de mão-de-obra para o cultivo da cana. Dom Luciano Duarte explicita o plano inicial:

Poderíamos adquirir terra e dividir com as famílias pobres, cerca de quatro tarefas para cada uma (pouco mais de um hectare). Assim, poderiam plantar ali, com tranquilidade, cereais para alimentação da família, o que viria completar o magro salário ganho nas Usinas e nas fazendas, as quais, na maioria, atravessavam situação econômica decadente e precária (DUARTE, 1978, p. 6).

Além de ter buscado apoio dos fazendeiros da região, Dom Luciano também passou a dialogar com seus amigos do campo intelectual sergipano, com o propósito de formar uma equipe que conseguisse gestar a nova instituição ou para pensar em possíveis soluções para os problemas apresentados no "grito de angústia”. Um dos primeiros contatos foi com a professora do curso de Serviço Social, Maria Luíza de Souza, que prontamente aceitou o desafio. Ao longo dos primeiros anos, a equipe de trabalho foi se constituindo, com a inserção de novos membros, como Enrica Mininni (desde 1969), Wollmer Bonfim, Emmanuel Franco e José Varjão dos Santos. A presença de técnicos era de fundamental importância para êxito da proposta, pois a redução da pobreza na Cotinguiba não ocorreria 
apenas com a distribuição de terras, mas também por meio da qualificação do camponês para trabalhar com a terra e gerir a produção, assim como por meio de ações de melhoria das condições sanitárias, da saúde da família e do acesso à educação. De acordo com Maria Lúcia Berger, “através de Fazendas Comunitárias oferece ao agricultor não só a terra em que pode plantar, mas dá-lhe também assistência técnico-financeira e social, na qual está incluída a educação” (BERGER, 1982, p. 2).

O terceiro ponto de diálogo estabelecido por Dom Luciano foi com os representantes do poder público estadual. Afinal, a compra das fazendas para a distribuição de terras era um dos grandes entraves à implantação da reforma agrária e gerou desconfiança entre os próprios camponeses. O brilho da esperança não mais irradiava nos olhos dos trabalhadores rurais de Maruim. Duarte descreveu uma frase cética que ouviu de um lavrador: "Meu pai me dizia que o pai dele contava que desde o tempo do imperador Dom Pedro II que se promete terra para os camponeses, e nunca se viu nada, até que chegou a PRHOCASE” (DUARTE, 1978, p. 15).

Promessas não cumpridas permeavam as memórias aflitas e pouco esperançosas dos lavradores. A experiência dos camponeses era permeada por frustrações. As propostas de reforma agrária não passavam de discursos políticos, nunca empreendidos, nem tampouco transformados em política pública de governo. A PRHOCASE reverteu esse processo e começou a tornar os sonhos distantes em realidade. Contudo, faltava "o primeiro passo indispensável, sem o qual nada se fará de estável e sólido” (DUARTE, 1978, p. 6), a terra. Para obter os recursos necessários à aquisição da propriedade que se tornaria a primeira fazenda comunitária da PRHOCASE, Dom Luciano Duarte resolveu marcar uma audiência com Lourival Baptista, então governador do estado de Sergipe. 
Num fim de tarde de fevereiro de 1968, após a Santa Missa, fui falar com o Governador Lourival Baptista, no Palácio Olímpio Campos. Ele ouviu-me, interessado. Concordou que, em matéria de promoção do camponês pobre de Sergipe, não se tinha feito quase nada. Estava informado da situação crítica de Maruim (DUARTE, 1978, p. 6).

Com a anuência do governador, a PRHOCASE finalmente poderia iniciar as suas atividades, com a compra de uma fazenda. A proposta inicial apresentada pelo bispo auxiliar era a formação de uma parceria entre o Estado e a Arquidiocese para a compra do terreno. Todavia, Lourival Baptista se comprometeu em arcar a aquisição da primeira fazenda com verbas exclusivas dos cofres públicos, no valor de 65 mil cruzeiros. Desse modo, se firmava a aliança que se tornaria o tripé fundamental da instituição ao longo de seus 20 anos de atuação: Igreja, Estado e lideranças civis. Maria Lúcia Souza Ramos Berger informa:

além do Governo Estadual, participaram na organização e implantação da entidade, latifundiários da região, a Prefeitura do Município, que contribuiu com a doação de mais de 100 tarefas de terra e uma casa de farinha, e muitas entidades tais como o Serviço Social da Indústria, que doou um transporte à entidade (BERGER, 1982, p. 95).

Com a compra das fazendas, foi realizada uma sessão solene no auditório do Instituto Histórico e Geográfico de Sergipe, na noite do dia 30 de março de 1968. Esse evento foi de fundamental importância, pois reunia as autoridades civis do Estado e da Igreja que estavam à frente da PRHOCASE, assim como os lavradores de Maruim. "O grito de angústia", ${ }^{12}$ outrora sussurrado nos campos e ruelas de Maruim, ecoava pelo salão nobre de uma das principais instituições culturais da capital sergipana, no espaço onde, 45 dias depois, sob a também liderança de Dom Luciano, reuniria os principais nomes da intelectualidade local para a implantação da Universidade Federal de Sergipe. ${ }^{13}$ No entender de Dom Luciano Duarte, aquele momento foi oportuno, pois:

\footnotetext{
${ }^{12}$ Termo utilizado por Dom Luciano Dom Luciano Duarte para designar a experiência dos excluídos na região da Cotinguiba.

${ }^{13}$ Foi implantada no dia 15 de maio de 1968.
} 
Permitiu ao Governador ouvir, pela voz dos próprios agricultores pobres, o relato de suas angústias. Os "sem voz" começavam a falar e a ser escutados. Fatos dramáticos foram contados, na linguagem rude e despojada dos pobres. Seu desencanto. Seu sofrimento. Seu desamparo. E agora o estremecer de uma súbita esperança que lhes chegava e que eles contavam não os decepcionaria.

O Governador Lourival Baptista comoveu-se. Em seu discurso de encerramento fez a afirmação decisiva: "Restam-me três anos, dos quatro de meu mandato de Governador. Em cada um desses anos, surgirá uma Fazenda Comunitária da PRHOCASE, para os camponeses pobres. A de Maruim é a primeira" (DUARTE, 1978, p. 8).

A noite foi de grandes expectativas para os lavradores e paulatinamente cessava o ceticismo vigente. Finalmente, os clamores dos trabalhadores que passariam a ser vistos como "os agricultores de Dom Luciano" não ficaram restritos a Maruim. Nos anos subsequentes, novas narrativas seriam contadas. Novos dramas seriam expostos. A experiência social dos expropriados se tornaria a arma na luta pela terra. "O grito de angústia" ecoaria pela Cotinguiba, semeando a esperança. A PRHOCASE se tornaria o principal símbolo da conquista pela terra e levaria trabalhadores rurais de outras cidades da Cotinguiba a reivindicarem a presença do prelado para a garantia do direito à propriedade.

\section{Conclusões}

A PRHOCASE foi criada em 1967 a partir de uma situação de conflito envolvendo os trabalhadores rurais da região da Cotinguiba e as elites políticas da localidade. Certamente, essa experiência pode ser entendida como um ato inaugural no processo de constituição de uma política pública voltada para a reforma agrária em Sergipe. Neste processo, um papel relevante foi desempenhado pelo então bispo auxiliar da Arquidiocese de Aracaju, Dom Luciano José Cabral Duarte, que passou a intervir no processo de negociação envolvendo os trabalhadores e as elites.

Dessa negociação emergiu a PRHOCASE, inicialmente como uma proposta que atendia aos interesses dos latifundiários, com a distribuição de lotes de terras 
que pudessem apenas “complementar a renda dos parcos salários recebidos". Essa condição tornou-se um elemento que propiciava uma melhor aceitação da proposta entre os fazendeiros da região, bem como entre as autoridades políticas. Todavia, ainda nos primeiros anos de atuação, o bispo auxiliar e a sua equipe de voluntários, ao analisar os resultados das experiências das primeiras famílias alocadas na fazenda comunitária, perceberam que essa proposta era ineficiente para a construção da autonomia. Diante dessa constatação, os propósitos da instituição foram revistos e os lotes ampliados, no sentido de promover a autonomia das famílias a partir do trabalho exclusivo em suas propriedades.

Com isso, o processo de criação da PRHOCASE revela um contexto social e político complexo, bem como nos apresenta sujeitos escorregadios com atuação ambígua, no processo de negociação que, por vezes, pendem para a manutenção da ordem, em outros casos tendem a promover mudanças no quadro social. Trata-se de uma instituição ambivalente, permeada de interferências dos inúmeros setores que estiveram envolvidos em sua gestação, como os trabalhadores rurais, o Estado, a elite açucareira, o arcebispado e empresários da capital sergipana. De qualquer modo, essa experiência engendrada por um religioso tido como o mais conservador do clero sergipano tornou-se uma eficiente proposta pensada dentro da ordem, na erradicação da pobreza na sociedade sergipana da segunda metade do século XX.

\section{REFERÊNCIAS}

ANDRADE, Manuel Correia de. Lutas Camponesas no Nordeste. São Paulo: Ática, 1989.

ALMEIDA, Adroaldo da Silva. "Pelo Senhor, marchamos": os evangélicos e a ditadura militar no Brasil (1964-1981). Niterói/RJ, 310f. Tese (Doutorado em História). UFF, 2016.

ALMEIDA, Maria da Glória Santana de. Uma unidade açucareira em Sergipe: o Engenho Pedras. In: PAULA, Eurípedes Simões de (org.). A propriedade rural: Anais do VIII Simpósio dos Professores Universitários de História. Vol. 2. São Paulo, 1978.

AZZI, Riolando. A Sé Primacial de Salvador: a Igreja Católica na Bahia (1551-2001). Petrópolis/RJ: Vozes, 2001. 
BERGER, Maria Lúcia Souza Ramos. A educação de adultos numa experiência de reforma agrária: o caso da Promoção do Homem do Campo de Sergipe - PRHOCASE. João Pessoa, 248f. Dissertação (Mestrado em Educação), UFPB, 1982.

CORTEZ, Lucili Grangeiro. O drama barroco dos exilados do Nordeste. Fortaleza: EDUECE, 2005.

DANTAS, Ibarê. A tutela militar em Sergipe (1964-1984). São Cristóvão: EDUFS, 2014.

DANTAS, Ibarê. História de Sergipe: República (1889-2000). Rio de Janeiro: Tempo Brasileiro, 2004.

DUARTE, Dom Luciano Cabral. PRHOCASE: uma experiência de promoção humana da Arquidiocese de Aracaju (Sergipe) - Brasil. PRHOCASE 10 anos: Promoção do Homem do Campo de Sergipe (1968-1978). Aracaju, 1978.

FEITOSA, Cid Olival. As transformações recentes na economia sergipana: 19702005. Campinas-SP, 229f. Dissertação (Mestrado em Desenvolvimento Econômico) Unicamp, 2007, p. 35.

FERNANDES, Maria José Costa. Reforma agrária e assentamentos rurais no Rio Grande do Norte: algumas reflexões. Revista Contexto, Natal, v. 4, n. 1-2, 2013.

MELO, Ricardo Oliveira Lacerda de. Industrialização e integração econômica no Nordeste: o caso da indústria têxtil. Campinas-SP, 186f. Dissertação (Mestrado em Economia). Unicamp, 1987.

MONTEnEGRO, Antônio Torres. História, Metodologia e Memória. São Paulo: Contexto, 2010.

MORAIS, Gizelda. D. Luciano José Cabral Duarte: relato biográfico. Aracaju: J. Andrade, 2008.

NASCIMENTO, Antônio José. Economia sergipana e a integração no mercado nacional (1930-1980). Campinas-SP, 229f. Dissertação (Mestrado em Teoria Econômica) Unicamp, 1994.

NUNES, Maria Thétis. História de Sergipe a partir de 1820. Rio de Janeiro: Cátedra, 1978.

PASSOS SOBRINHO, Josué Modesto dos. Reordenamento do trabalho: trabalho escravo e trabalho livre no Nordeste açucareiro (Sergipe, 1850-1930). Aracaju: FUNCAJU, 2000.

RESENDE, José Mário dos Santos. Entre campos e veredas da Cotinguiba: o espaço agrário em Laranjeiras (1850-1888). São Cristóvão/SE. Dissertação (Mestrado em Geografia). UFS, 2003. 
SALES, Dom Eugênio. Dom Eugênio explica a origem do Movimento de Natal. In:

Diocese de Natal: edição comemorativa do Centenário. Natal, 2009.

SANTOS, M. F. J. "O bispo da terra” e as agruras dos camponeses sergipanos: escrita biográfica e reinvenção de si. Revista Brasileira de História das Religiões, Paraná, v. 9, n. 26, 2016.

SILVA, Osvaldo Heller. A foice e a cruz: comunistas e católicos na história do sindicalismo dos trabalhadores rurais do Paraná. Curitiba: Rosa de Bassi, 2006.

ZACHARIADHES, Grimaldo Carneiro. "Dom Avelar Brandão Vilela e a Ditadura Militar". In: ZACHARIADHES, Grimaldo Carneiro (org). Ditadura Militar na Bahia: Novos olhares, novos objetos, novos horizontes. Salvador: EDUFBA, 2009. 